of the facilities provided, all general practitioners, paediatricians, and district medical officers in the county were circularized. They were informed of the existing provisions for the mentally handicapped in the county, and were advised that if they wished to refer such patients, and their parents, to the county medical officer, arrangements would be made for them to be seen at their county health clinic by the medical officer for mental health. In addition, discussions have been held with groups of health visitors to help them recognize mental subnormality.

Since this service commenced there have been 29 referrals, 18 from general practitioners, eight from district medical officers, and three from paediatricians. Seventeen (more than half the total) were children aged 5 years or less, of whom six were 2 years or less.

As regards recommendations, all parents were given advice and information as to the needs of the mentally handicapped and the likely rate of development. All were put in touch with the National Society for Mentally Handicapped Children. In other respects special recommendations as to admission to training centres or residential units were similar to the recommendation in Dr. Kirman's series. In a few cases hospital care, either permanent or short-term, was required, and such were referred to the out-patient clinic conducted by the consultants of the hospital for the subnormal which serves this county.

This service has been welcomed by the parents, many of whom had not previously received any accurate advice or information about mental handicap, and the community services. Also, it was welcomed by the general practitioners, who were interested to receive information about the provisions in the community for the mentally handicapped. -I am, etc.,

County Hall,
Nottingham.

Eva RoIth

\section{Phenylbutazone and Acute Leukaemia}

SIR,-We have previously reported ${ }^{1}$ that 8 out of 55 cases of acute leukaemia in adults studied between April 1959 and mid1963 had a history of phenylbutazone ingestion. Of these three were excluded from the calculations (two because they had received radiotherapy and one because of the brevity of the period of ingestion before the diagnosis of leukaemia). This number, 5 out of 55 (9\%), compared with a similar history in 5 out of $417(1.2 \%)$ cases of chronic leukaemia, lymphoma, and allied disorders.

The significance of these findings has been debated, and a suggestion has been made that the difference between the two groups may be due to disparity in age structure. The statistics for the five-year period 1959-63 inclusive are now available, and the age structure of the two groups is presented in Table I.

\begin{tabular}{|c|c|c|c|c|c|c|c|c|}
\hline Group & $\begin{array}{l}20- \\
29\end{array}$ & $\begin{array}{r}30- \\
39\end{array}$ & $\begin{array}{l}40- \\
49\end{array}$ & $\begin{array}{l}50- \\
59\end{array}$ & $\begin{array}{c}60- \\
69\end{array}$ & $\begin{array}{l}70- \\
79\end{array}$ & $80+$ & Total \\
\hline $\begin{array}{l}\text { Acute } \\
\text { leukaemia } \\
\text { Allied } \\
\text { disorder }\end{array}$ & $\begin{array}{r}7 \\
20\end{array}$ & $\begin{array}{l}13 \\
34\end{array}$ & $\begin{array}{r}9 \\
49\end{array}$ & $\begin{array}{l}11 \\
64\end{array}$ & 13 & 18 & 4 & 75 \\
\hline
\end{tabular}

Chi-square $=7.388$ on 6 d.f. Not significant.
The two groups may be considered sufficiently alike for comparisons to be made regardless of the age eff ect.

As can be seen from Table I an additional 20 cases of acute leukaemia were recorded at the end of 1963, and none of these had a history of phenylbutazone ingestion. Only those patients with allied disorders whose condition has been confirmed by a panel of pathologists are included in the present calculations, whereas in the previous report all cases to be notified to the registry were counted.

Five of the 75 cases of acute leukaemia had a history of phenylbutazone ingestion $(6.67 \%)$, compared with 5 of 367 " control" cases $(1.36 \%)$ - and the difference in these proportions is significant at the 0.05 level (Table II).

TABLE II.-History of Phenylbutazone Ingestion

\begin{tabular}{rr|r|r|r|r} 
& & & Yes & No & Total \\
\hline $\begin{array}{ccc}\text { Acute leukaemia } \\
\text { Allied disorder . }\end{array}$ & $\ldots$ & Yes & 5 & 70 & 75 \\
\hline Total .. &.. & & 10 & $\mathbf{4 3 2}$ & $\mathbf{4 4 2}$
\end{tabular}

Chi-square $(C)=5 \cdot 706(P$ less than $0 \cdot 05)$.

Although these statistical tests confirm the difference in phenylbutazone ingestion between patients with acute leukaemia and those with allied disorders, they do not allow any conclusions to be made concerning the possible leukaemogenicity of the drug.

A study of patients during the period 1964-5 and including "controls" from the general population is at present in progress. -We are, etc.,

\section{N. S. STENHOUSB. \\ J. A. Sims. \\ L. Dougan. \\ H. J. WOODLIFP.}

Department of Haematology,

Royal Perth Hospital,
Western Australia.

\section{REPERENCB}

Woodliff, H. J., and Dougan, L., Brit. med. J.,
1964, 1, 744.

\section{Treatment of Localized Myxoedema}

SIR,-Like Drs. R. Hall, G. Holti, and C. J. Stevenson (4 December, p. 1368) I was surprised to find no mention of the longacting thyroid stimulator (L.A.T.S.) in your leading article on localized myxoedema (13 November, p. 1138), but I cannot go all the way with them. I have tried systemic and local corticoids (by inunction and multiple acupuncture) with and without, usually without, success and I have scored one success with a polythene bag worn on one leg at night without a local corticoid. I have used $x$-ray therapy, ultra-violet radiation, diathermy over Miller's bandages, hyaluronidase by multiple acupuncture and by infusion into the femoral artery, and every available analogue of thyroxine both locally and systemically. None of these methods has been consistently successful. On the other hand, I have seen several spontaneous recoveries.

Last month at the Royal Society of Medicine I showed a patient with Hashimoto's disease, exophthalmos, acropachy, and very severe localized myxoedema. who had also a very high titre of L.A.T.S. in her plasma. The leg more severely affected had been treated by all the above remedies without result. I decided to treat it by the local application of dimethyl sulphoxide.

This substance is an industrial solvent known for a century. It has been used in various disorders of the skin and has been regarded as non-toxic. It easily penetrates the skin and is a solvent of mucopolysaccharides. It therefore occurred to me that it might be effective in localized myxoedema, a condition in which, I believe, it has not previously been tried. In the patient described the results were highly satisfactory.

Unfortunately it has recently been reported that dimethyl sulphoxide causes damage to the eyes of rabbits but not of other animals tested, and no detriment has occurred in monkeys or men. Nevertheless, I have thought it wise, despite the protests of the patient, to discontinue the experiment.

It may be found that dimethyl sulphoxide is harmless to man. In that event it may prove to be by itself, as in my solitary case, effective in localized myxoedema. It may also prove to be an effective vehicle for the passage through the skin of other theoretically possible remedies such as hyaluronidase or corticosteroids.

It seems unlikely that this is the answer to the problem of localized myxoedema. It may prove an effective temporary remedy simply because it dissolves mucopolysaccharides. Experience of other occasionally successful remedies suggests that it may not always work. We are left with a problem more important than the occasional relief of the occasional patient. Why does it happen anyway ?-I am, etc.,

\section{Department of Endocrinology,} London N.W.3. Raymond Greene.

\section{Hypochondriasis}

SiR,-In your issue of 25 December (p. 1547) Dr. B. C. McCaffrey suggests that some of the hypochondriacal patients we recently described ${ }^{1}$ might have been schizophrenics. This is most unlikely, as the subjects of our report were selected from among a larger number precisely because the diagnosis of an affective disorder could be made with confidence.

On the other hand, among those referred to our special clinic and not included in our paper were two middle-aged patients, one definitely and the other possibly schizophrenic: the former, incidentally, had extensive paranoid features in addition to his hypochondriasis, a combination that Bleuler ${ }^{2}$ thought never occurred. It may be that at follow-up additional cases of schizophrenia may emerge, especially among young men having panic attacks about their health, but our present evidence suggests that among the undiagnosed chronic attenders at general huspital out-patient departments schizophrenia is much less likely to be encountered than affective disorders, anxiety states, and obsessional neuroses.-I am, etc.,

\section{Graylingwell Hospital,} Sussex.

\section{REPERENCES}

Kreitman, N., Sainshury, P., Pearce, K., and Costain, W. R.. Brit. Y Psychol., 1965. 111. 607. Bleuler, E., Dementia Pruecox or the Group of Schizophrenias, 1950. Monograph Ser 